https://helda.helsinki.fi

\title{
Automated on-line isolation and fractionation system for nanosized biomacromolecules from human plasma
}

\section{Multia, Evgen}

2020-10-06

Multia , E , Liangsupree , T , Jussila , M , Ruiz-Jimenez , J , Kemell , M \& Riekkola , M-L 2020 , ' Automated on-line isolation and fractionation system for nanosized biomacromolecules from human plasma ', Analytical Chemistry , vol. 92 , no. 19 , pp.

13058-13065 . https://doi.org/10.1021/acs.analchem.0c01986

http://hdl.handle.net/10138/321821

https://doi.org/10.1021/acs.analchem.0c01986

cc_by

publishedVersion

Downloaded from Helda, University of Helsinki institutional repository.

This is an electronic reprint of the original article.

This reprint may differ from the original in pagination and typographic detail.

Please cite the original version. 


\title{
Automated On-Line Isolation and Fractionation System for Nanosized Biomacromolecules from Human Plasma
}

\author{
Evgen Multia, Thanaporn Liangsupree, Matti Jussila, Jose Ruiz-Jimenez, Marianna Kemell, \\ and Marja-Liisa Riekkola*
}

Cite This: Anal. Chem. 2020, 92, 13058-13065

Read Online

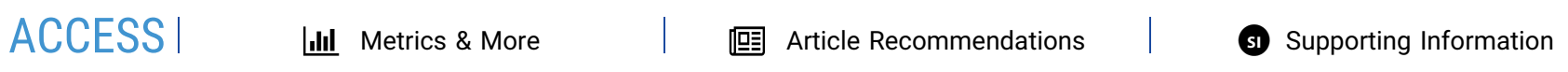

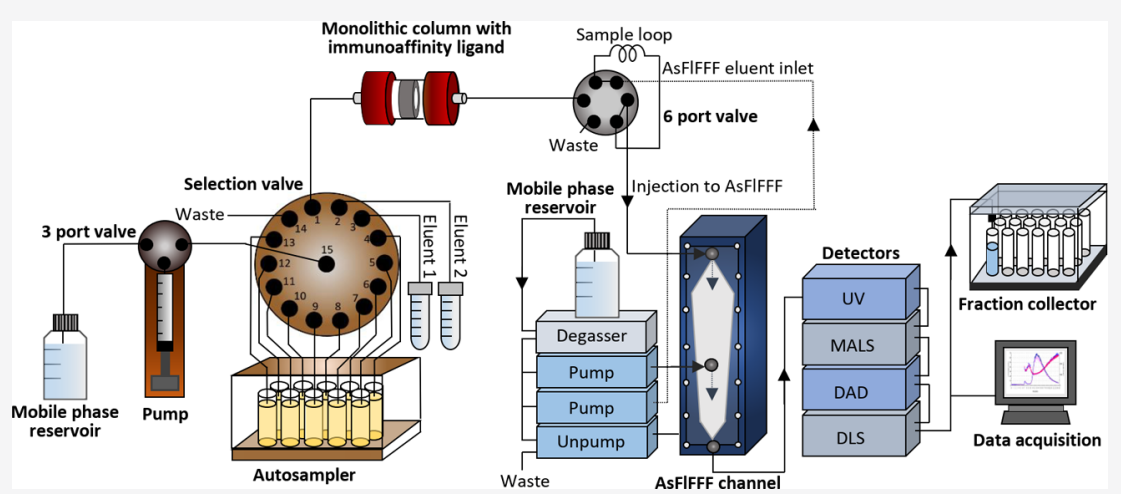

ABSTRACT: An automated on-line isolation and fractionation system including controlling software was developed for selected nanosized biomacromolecules from human plasma by on-line coupled immunoaffinity chromatography-asymmetric flow field-flow fractionation (IAC-AsFlFFF). The on-line system was versatile, only different monoclonal antibodies, anti-apolipoprotein B-100, anti-CD9, or anti-CD61, were immobilized on monolithic disk columns for isolation of lipoproteins and extracellular vesicles (EVs). The platelet-derived CD61-positive EVs and CD9-positive EVs, isolated by IAC, were further fractionated by AsFlFFF to their sizebased subpopulations (e.g., exomeres and exosomes) for further analysis. Field-emission scanning electron microscopy elucidated the morphology of the subpopulations, and 20 free amino acids and glucose in EV subpopulations were identified and quantified in the $\mathrm{ng} / \mathrm{mL}$ range using hydrophilic interaction liquid chromatography-tandem mass spectrometry (HILIC-MS/MS). The study revealed that there were significant differences between EV origin and size-based subpopulations. The on-line coupled IAC-AsFlFFF system was successfully programmed for reliable execution of 10 sequential isolation and fractionation cycles (37-80 min per cycle) with minimal operator involvement, minimal sample losses, and contamination. The relative standard deviations (RSD) between the cycles for human plasma samples were $0.84-6.6 \%$.

$\mathrm{H}$ uman biomacromolecules are complex and structurally diverse. They are excellent biomarkers, needed for the recognition and detection of the early stages of diseases, to understand the pathogenesis of the disease, and to find the treatment solutions. Their fast and reliable isolation and purification are often challenging or even a bottleneck for their diagnostic and therapeutic applications. ${ }^{1}$ The challenges are caused by their stability requirements and unique nature, especially when isolated from human biofluids. New systems are needed to eliminate the problems, such as operator dependent errors, ${ }^{2}$ aggregation, ${ }^{3,4}$ oxidation, shear and mechanical stress, and contamination, ${ }^{5}$ present in the current methods and techniques, which are often also tedious and time consuming.

The study of subpopulations of lipoproteins and extracellular vesicles (EVs) has proven to be important for detection of different diseases ${ }^{6,7}$ (e.g., small dense low-density lipoprotein (LDL) particles are considered unfavorable for health ${ }^{8,9}$ ), or for finding a new extracellular vesicle subpopulation called exomere, ${ }^{10}$ whose effects on health are still unclear. EV is a general term that includes both ectosomal and endosomal EVs (exosomes). Their size and other biophysical characteristics are similar, and thus EVs and exosomes cannot be separated based on size or density alone. ${ }^{11}$ Therefore specific immunobased separation techniques are needed for future clinical diagnostic and therapeutic applications of exosomes, ${ }^{6,11,12}$ and especially the study of subpopulations of EVs has lately attracted great attention. , $^{6,13}$

Received: May 8, 2020

Accepted: September 7, 2020

Published: September 7, 2020 


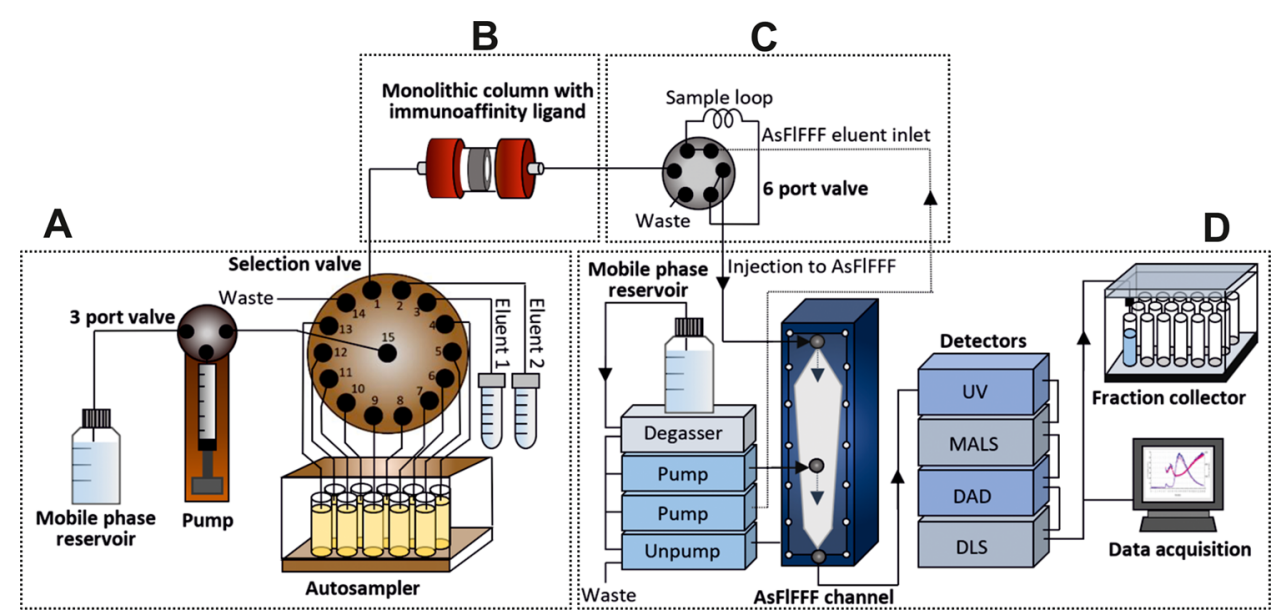

Figure 1. Automated on-line system for the isolation of nanosized biomacromolecules. The system consisted of a selection valve for controlling the isolation process (A), a monolithic column for IAC (B), an automated six port valve for injection to AsFlFFF (C), and AsFlFFF with UV, MALS, $\mathrm{DAD}$, and DLS detectors, and a fraction collector (D).

Selective and high yield isolation of nanosized biomacromolecules (e.g., lipoproteins and EVs) from human biofluids, such as plasma, is a challenging task due to the complex nature of sample matrices. Immunoaffinity chromatography (IAC) with polymer-based monolithic columns has proven to be a valuable tool for selective isolation of these biomacromolecules. ${ }^{13,14}$ However, the need for the clarification of characteristics of heterogeneous subpopulations, and for the deep understanding of their effects on human health, calls for further fractionation and analysis. Asymmetrical flow field-flow fractionation (AsFlFFF) combined with light-scattering detectors has already demonstrated its importance in off-line fractionation of biomacromolecules, ${ }^{15,16}$ lipoproteins, ${ }^{3}$ and EVs by helping to shed light on the nature of their subpopulations. ${ }^{10,13}$ Furthermore, the on-line coupling of different techniques has offered extra advantages, such as ease of automation and high reproducibility, usually resulting in a short analysis time. ${ }^{2}$

In this work, a novel automated on-line isolation and fractionation IAC-AsFlFFF system was constructed for the isolation and fractionation of EVs, exosomes, exomeres, and apolipoprotein B-100 (apoB-100) containing lipoproteins from challenging human plasma. The system was equipped with multiple detectors, such as ultraviolet, multiangle lightscattering, dynamic light-scattering, and diode array detectors (UV, MALS, DLS, and DAD) to provide more information on the chemical and physical characteristics of biomacromolecules. Field-emission scanning electron microscopy (FESEM) gave morphology information of the fractionated EV subpopulations. Their surface charge was revealed by $\zeta$ potential measurements. The free amino acid and glucose composition of the isolated EV subpopulations was elucidated by hydrophilic interaction liquid chromatography-tandem mass spectrometry (HILIC-MS/MS), and these results were subjected to statistical analysis for obtaining extra information on EV subpopulations.

\section{EXPERIMENTAL SECTION}

Chemicals and Reagents. The details are given in the Supporting Information.

Instrumentation. The details are given in the Supporting Information.
Preparation of Solutions. Phosphate buffered saline (PBS) solution was prepared by dissolving a PBS tablet in $200 \mathrm{~mL}$ of MilliQ (MQ) water and filtered through a $0.2 \mu \mathrm{m}$ membrane filter (Supor-200). Carbonate-bicarbonate solution (0.1 M, pH 11.3) was prepared by mixing $\mathrm{Na}_{2} \mathrm{CO}_{3}$ solution $(90 \mathrm{~mL}$ of $0.1 \mathrm{M})$ with $\mathrm{NaHCO}_{3}$ solution $(10 \mathrm{~mL}, 0.1 \mathrm{M})$. The $\mathrm{pH}$ of the solution was adjusted to 11.3 with $1 \mathrm{M} \mathrm{NaOH}$. $\mathrm{NH}_{4} \mathrm{OH}(0.15 \mathrm{M}, \mathrm{pH} 11.5)$ was prepared by diluting with 1.13 $\mathrm{mL}$ of $25 \%$ ammonia solution to a final volume of $50 \mathrm{~mL}$ with MQ water. The HILIC-MS/MS mobile phase A was prepared by adding $1 \mathrm{~mL}$ of formic acid to acetonitrile $(999 \mathrm{~mL})$ and the mobile phase $\mathrm{B}$ was prepared by adding $1 \mathrm{~mL}$ of formic acid to MQ water $(999 \mathrm{~mL})$. All standards and internal standards were prepared in mobile phase B.

On-Line IAC-AsFIFFF System. An on-line IAC-AsFIFFF system is depicted in Figure 1. In addition to a monolithic disk column and AsFlFFF, the system was composed of: (i) an inhouse built pump with a $5 \mathrm{~mL}$ glass syringe driven by a stepping motor and a three-port valve with an electrical actuator for dispensing the solutions, (ii) a Cheminert C25Z31814D (Vici AG, Schenkon, Switzerland) 14 position stream selection valve connected to an EMHMA-CE microelectric valve actuator (Vici AG, Schenkon, Switzerland) for selection of samples and eluents, and (iii) a six-port medium pressure injection valve V-451 (IDEX Upchurch Scientific, Oak Harbor, WA) connected to a Model E60 actuator (Vici AG, Schenkon, Switzerland) for the introduction of the sample to AsFlFFF. The setup was controlled by a Raspberry Pi (Model B Rev. 2.0) single board computer running on in-house written Python scripts on Raspbian (ver.joo ot 9 Stretch) operating system.

The selection valve was used for controlling the isolation process (Figure 1A), which included a $5 \mathrm{~mL}$ syringe pump and an autosampler for 10 samples. Process automation and control of the isolation process were performed using customized software. A three-port valve was used to connect the mobile phase reservoir to the syringe pump. The IAC based isolation included a monolithic column with immobilized immunoaffinity ligand (Figure 1B). The elution conditions to release the isolates from the column, immobilized with antibodies, were optimized in our previous studies. ${ }^{13,14}$ With an automated six port valve we connected monolithic column on-line to AsFlFFF (Figure 1C). The 
injection steps were controlled by a timer in our software that turned the valve and started the AsFlFFF run after the biomolecules entered the sample loop. This minimized the time under high $\mathrm{pH}$ conditions. AsFlFFF was utilized for characterization and provided valuable information on the size distribution and concentration of different subpopulations of the biomacromolecules with MALS, DLS, UV, and DAD detectors, and gentle fractionation of the isolates (Figure 1D). The fractions were collected with a fraction collector in a physiological buffer (PBS) for further analysis and characterization.

Scanning Electron Microscopy (SEM). Preconcentrated combined fractions of EV subpopulations were dried on clean polished silicon wafer surfaces. The samples were then coated with a $3 \mathrm{~nm} \mathrm{Au}-\mathrm{Pd}$ alloy using a Cressington 208HR high resolution sputter coater and imaged at $3 \mathrm{kV}$ with secondary electrons.

Hydrophilic Interaction Liquid ChromatographyTandem Mass Spectrometry (HILIC-MS/MS). Amino Acids and Glucose Extraction. CD9- and CD61-positive $\left(\mathrm{CD}^{+}\right.$and $\mathrm{CD}^{+} 1^{+}$) EV fractions were subjected to preconcentration and salt removal with disposable Nanosep centrifugal devices with $10 \mathrm{~K}$ molecular weight cutoff membrane filters at $14000 \mathrm{~g}$ for $2 \mathrm{~min}$ for each $500 \mu \mathrm{L}$ fraction at room temperature. The filtrate was discarded. Thereafter, cold acetonitrile $(50 \mu \mathrm{L})$ was added to the membrane for EV lysis and removal of precipitated proteins. Cold acetonitrile precipitated proteins effectively from human plasma $^{17}$ and lysed the lipid bilayer membranes. ${ }^{18}$ After vortexing, the filter unit was centrifuged for another $2 \mathrm{~min}$ at $14000 \mathrm{~g}$. The filtrate was then collected, and the ISTD mixture which yielded the final concentration of $1 \mathrm{ppm}$ of amino acids (glycine-2,2- $d_{2}$, L-phenylalanine-3,3- $d_{2}$, and L-lysine-4,4,5,5- $d_{4}$ ) and $5 \mathrm{ppm}$ of D-fructose-13C6 in MQ water containing $0.1 \%$ formic acid was added to the filtrate for HILIC-MS/MS analysis.

Determination of Amino Acids and Glucose by HILIC-MS/ MS. The method used for the determination of amino acids and glucose was based on our previously developed method ${ }^{19}$ with some modifications. The column temperature was set to $50{ }^{\circ} \mathrm{C}$. Mobile phase A was acetonitrile with $0.1 \%$ formic acid, and mobile phase B was MQ water with $0.1 \%$ formic acid. The separation of the target analytes was performed using the following gradient program $20 \%$ B for $15 \mathrm{~min}(0.4 \mathrm{~mL} / \mathrm{min})$, $20-80 \% \mathrm{~B}$ for $5 \mathrm{~min}(0.3 \mathrm{~mL} / \mathrm{min})$, followed by $80-20 \% \mathrm{~B}$ for $3 \mathrm{~min}(0.3 \mathrm{~mL} / \mathrm{min})$. The injection volume was $3 \mu \mathrm{L}$ for all samples. The effluent was electrosprayed, ionized (positive and negative mode for amino acids and sugars, respectively), and monitored by $\mathrm{MS}^{2}$ detection in the multiple reaction monitoring mode (MRM), with the exception of glucose, which was analyzed in the single ion monitoring mode. Ionization conditions and MRM parameters for different compounds are given in Table S1.

Total Protein and Total Cholesterol Analysis. Total cholesterol (free and esterified) concentrations in samples were measured using the Roche Cholesterol CHOD-PAP reagent (Kit no. 1489232; Roche, Germany) according to the manufacturer's protocol. The absorbance was measured with an EnSpire multimode plate reader (PerkinElmer Inc.) at 510 $\mathrm{nm}$. Total protein concentrations (concentration range: $0.1-$ $1.0 \mathrm{mg} / \mathrm{mL}$ ) were measured using a Bio-Rad DC Protein Assay Kit (Bio-Rad Laboratories, Hercules, CA) based on the Lowry method $^{20}$ at $750 \mathrm{~nm}$ and Pierce ${ }^{\mathrm{TM}} \mathrm{BCA}$ Protein Assay Kit
(Item no. 23225; Thermofisher Scientific) (for concentrations lower than $0.1 \mathrm{mg} / \mathrm{mL}$ ) based on bicinchoninic assay $(\mathrm{BCA})^{21}$ at $550 \mathrm{~nm}$ according to the manufacturer's protocols. Calibration curves and sample concentrations were calculated using EnSpire multilabel analyzer version 4.13.3005.1482.

Statistical Analysis. Different R 3.6.3 statistical analysis tools were used in this research. Skewness and Kurtosis tests for data distribution evaluation, principal component analysis (PCA) for visualization of differences between $\mathrm{CD}^{+}$and $\mathrm{CD}^{+} 1^{+} \mathrm{EV}$ subpopulations, and linear discriminant analysis (LDA) for statistical confirmation of these differences, including clarification of the variables involved in the process. Additional studies were also made to evaluate the potential differences between EVs of different sizes (PCA and LDA). ${ }^{22}$

In all of the cases, the concentrations of the free amino acids present in the EVs normalized by the total amount of protein were exploited as input variables for the development of the statistical models. Additional root square transformation was needed to provide normal data distribution of the input variables.

\section{RESULTS AND DISCUSSION}

In this section, we describe the automated on-line IACAsFlFFF system and its application for the isolation and fractionation of nanosized biomacromolecules. Because in our previous studies ${ }^{13,14}$ the IAC method was developed for the isolation of LDL particles in plasma, we tested the applicability of the on-line IAC-AsFlFFF system first to lipoproteins. Then the study was focused on the isolation and fractionation of the subpopulations of $\mathrm{CD} 9^{+}$and $\mathrm{CD} 61^{+} \mathrm{EVs}$, further characterized by FESEM and surface charge measurements. In addition, more in-depth vesicular free amino acid and glucose composition was clarified by HILIC-MS/MS.

Isolation and Fractionation of Human apoB-100 Containing Lipoproteins, and $\mathrm{CD}^{+}, \mathrm{CD} 1^{+} \mathrm{EVs}$ by the On-line IAC-AsFIFFF System. Three different monolithic disk columns for the IAC were immobilized with anti-apoB100, anti-CD9, and anti-CD61 according to our previous protocols. ${ }^{13,14}$ IAC process cycles (Figure S1) for the isolation of apoB-100 containing lipoproteins, $\mathrm{CD}^{+}$, and $\mathrm{CD}^{+} 1^{+} \mathrm{EVs}$ can be found in Table S2. The repetition of the experiments is shown in Figure S1, where the regeneration and waiting periods were taken into account for the AsFlFFF to be ready for the next fractionation. The total time for apoB-100 lipoprotein isolation and regeneration of the disk column was $16.5 \mathrm{~min}$ ( $1 \mathrm{~mL}$ sample injection, $3 \mathrm{~mL}$ PBS wash, elution with $2 \mathrm{~mL}$ of $\mathrm{NH}_{4} \mathrm{OH}$, and $3 \mathrm{~mL}$ PBS wash). Isolation and regeneration of the $\mathrm{EV}$ disks took $51 \mathrm{~min}$. The major difference between the isolations was that $\mathrm{EV}$ isolations had a larger sample volume $(5 \mathrm{~mL})$ and an additional $\mathrm{NH}_{4} \mathrm{OH}$ regeneration step (Eluent 1, Figure 1A), and carbonatebicarbonate solution (Eluent 2, Figure 1A) was used to elute the EVs. In our previous studies, ${ }^{14}$ we found that the carbonate-bicarbonate solution $(\mathrm{pH} 11.3)$ was able to elute LDL particles more specifically compared to $\mathrm{NH}_{4} \mathrm{OH}(\mathrm{pH}$ 11.3) with minimal nonspecifically bound particles, and other possible protein contaminants. Therefore, the carbonatebicarbonate solution was also used for selective elution of EVs in this study, while $\mathrm{NH}_{4} \mathrm{OH}$ was used for the elution of all apoB-100-containing lipoproteins from the anti-apoB-100 disk, and not only LDL. The flow rate for the apoB-100 containing lipoprotein isolation and elution was set to $0.5 \mathrm{~mL} / \mathrm{min}$, whereas it was $0.25 \mathrm{~mL} / \mathrm{min}$ for the $\mathrm{EV}$ isolation. The 


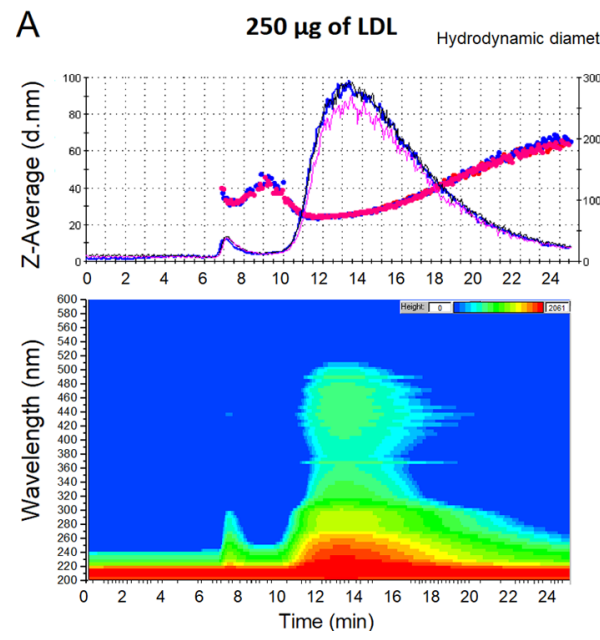

B apoB-100 containing lipoproteins isolated from plasma

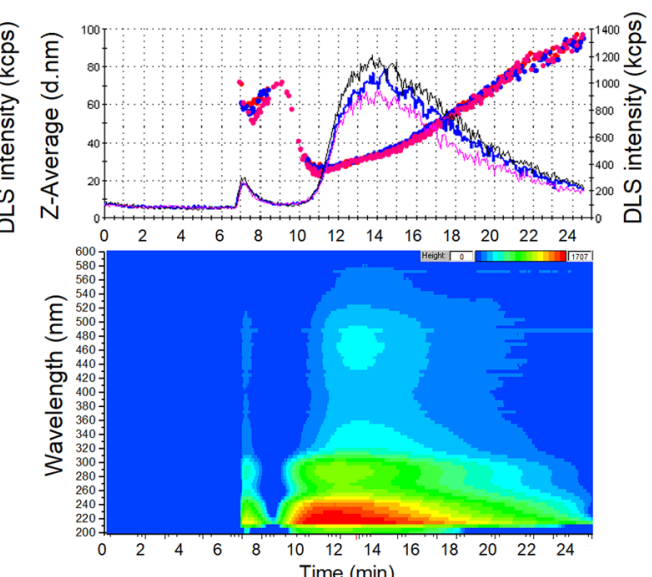

Figure 2. IAC-AsFlFFF analysis profiles after fractionating the anti-apoB-100 monolithic disk isolates. Technical replicates $(n=3)$ of raw flow DLS data, hydrodynamic diameter (dots as Z-Average) on the top, and isoabsorbance plot of selected run in the bottom, of preisolated LDLs (A) and apoB-100 containing lipoproteins isolated from human plasma (B).

regeneration step for $\mathrm{EV}$ disks before the analysis of the next sample was performed with $2 \mathrm{~mL}$ of $\mathrm{NH}_{4} \mathrm{OH}$ and $3 \mathrm{~mL}$ of PBS at a flow rate of $1 \mathrm{~mL} / \mathrm{min}$. No additional regeneration step was needed for the apoB-100 disk, since $\mathrm{NH}_{4} \mathrm{OH}$ was already used for elution. AsFlFFF run was automatically started after the eluent of IAC filled the sample loop $(500 \mu \mathrm{L})$ in the six port valve. The injection flow of $0.1 \mathrm{~mL} / \mathrm{min}$ was applied over 5 min during the focus mode at a cross-flow rate of $3 \mathrm{~mL} / \mathrm{min}$. PBS was used as an eluent in the AsFlFFF. The detector flow rate was set to $0.5 \mathrm{~mL} / \mathrm{min}$. A transition time of $1 \mathrm{~min}$ followed the focusing step. Biomolecules were subjected to high $\mathrm{pH}$ for only a few minutes before the buffer of the eluate was replaced with PBS.

Separation and fractionation with AsFlFFF of apoB-100 containing lipoproteins was achieved with 2 min linear decrease in cross-flow to $0.5 \mathrm{~mL} / \mathrm{min}$, followed by a linear decrease over $1-0 \mathrm{~mL} / \mathrm{min}$. After the cross-flow reached $0 \mathrm{~mL} / \mathrm{min}$, only the detector flow was applied for $15 \mathrm{~min}$. The total run time was $24 \mathrm{~min}$ and the fraction collection needed extra 2 min.

Separation and fractionation with AsFlFFF of $\mathrm{CD}^{+}$and $\mathrm{CD} 1^{+}$EVs (including their subpopulations of the size range of exosomes and exomeres) were carried out with 5 min linear decrease in cross-flow to $1.0 \mathrm{~mL} / \mathrm{min}$ after the focusing step, followed by a linear decrease over $15-0 \mathrm{~mL} / \mathrm{min}$. After the cross-flow reached $0 \mathrm{~mL} / \mathrm{min}$, only the detector flow was applied for $14 \mathrm{~min}$. The total run time was $40 \mathrm{~min}$ and extra 2 min was added for the fraction collector. The optimal AsFlFFF conditions are given in Table S3.

Optimization of the Six Port Valve Connection from IAC to AsFIFFF. The six port valve timer of the system for transferring the sample to AsFlFFF from the IAC (anti-apoB100 monolithic disk column) was optimized with $1 \mathrm{~mL}$ of 100 $\mu \mathrm{g} / \mathrm{mL}$ LDL samples ( $n=25$, isolated by ultracentrifugation). The biomolecules were eluted into the loop $(500 \mu \mathrm{L})$ of the six port valve, and after the transfer, the AsFlFFF run was started with the signal of the timer. The time which assured the highest sample concentrations (highest UV peak areas at 280 $\mathrm{nm}$ ) was selected (Figure S2) for all of the following experiments. The UV peak areas showed repeatability of $0.3-6.6 \%$ for each selected valve time.
Isolation and Fractionation of apoB-100 Containing Lipoproteins by IAC-AsFIFFF. To study the recovery of the system, three LDL samples of $1 \mathrm{~mL}$ with concentration of 250 $\mu \mathrm{g} / \mathrm{mL}$ (isolated from human plasma by ultracentrifugation, diluted with $\mathrm{PBS}$ to the required concentration) were captured and fractionated by IAC-AsFlFFF. The recovery was $99.6 \%$ based on DC protein assay and the samples contained $0.43 \pm$ $0.01 \mathrm{mg}$ of cholesterol. In addition, raw flow DLS data showed good repeatability of the isolation and fractionation (Figure 2A), while the RSD of the UV peak areas was $6.6 \%$. The hydrodynamic diameter $(24-28 \mathrm{~nm})$ of LDL particles at a retention time of $10-15 \mathrm{~min}$ agreed well the size range reported in the literature. ${ }^{8}$ Isoabsorbance plots of the DAD detector also allowed the detection of carotenoids (11-18 $\mathrm{min})$ in the LDL core $(430-500 \mathrm{~nm}){ }^{4}$ Most of the carotenoids were found at $12-15 \mathrm{~min}$, where most of the LDLs were retained. The tail of the DLS peak (Figure 2A) with a bigger size corresponds probably to fused LDL particles and LDL aggregates found in the sample.

The system was also used to study human plasma samples (1 $\mathrm{mL}$, dilution factor $1: 10$ in PBS) to verify the applicability of the system, giving $0.84 \%(n=3)$ for the RSD of UV peak areas. Not only the DLS and DAD analysis profiles resembled those of pure LDL, but also bigger sized particles were detected (Figure 2B), since the isolation with anti-apoB-100 monolithic disk was based on the recognition of the epitope of the apoB100. Chylomicrons, very-low-density lipoprotein (VLDL) particles, and their remnants (intermediate-density lipoprotein (IDL) particles) were also captured by the anti-apoB-100 disk, as confirmed by the hydrodynamic diameter of $95 \mathrm{~nm}$ obtained from the DLS data. The results agreed with our previous experiments. ${ }^{14}$ The IAC also trapped small LDL particles of under $24 \mathrm{~nm}$ (retention time 11-12 min, Figure 2B), which were not present in our ultracentrifugation method for LDL isolation described in Ref 23. The on-line system could successfully capture all major lipoproteins, ${ }^{8}$ except HDL, that went through the monolithic column. The carotenoids were also found in the plasma isolates (at retention time 11-22 $\mathrm{min}$ ), with the highest concentration at a retention time of 13 $\min$.

Isolation and Fractionation of $\mathrm{CD}^{+}$and $\mathrm{CD} 61^{+} \mathrm{EVs}$ by IAC-AsFIFFF. The system was utilized to study 
subpopulations of EVs. The CD61 antibody was used for platelet-derived EVs in the exosomal size range ${ }^{13}$ and the CD9 antibody was used for both EVs originating from multivesicular bodies (MVBs), ${ }^{23,24}$ as well as those $\mathrm{CD}^{+}$EVs not originating from MVBs, but having the size range of exosomes. ${ }^{6,25}$ Subpopulations were divided based on their sizes: $<50 \mathrm{~nm}$ for the size range of exomeres, and 50-80 and $80-120 \mathrm{~nm}$ for the size range of exosomes. ${ }^{10,13,26}$ Due to the pore size of monolithic disk columns $(1.3 \mu \mathrm{m}$ in diameter $)$, bigger sized EVs were excluded from being captured by the IAC (Figure $3 \mathrm{~A})$. Isoabsorbance plots indicated no contamination of the isolates from lipoproteins, since no carotenoids were detected by the DAD. The concentration of platelet-derived EVs in the exosomal size range was significantly lower compared to $\mathrm{CD}^{+}$ EVs (Figure 3B). The system could successfully and reproducibly isolate and fractionate the EVs, and FESEM of

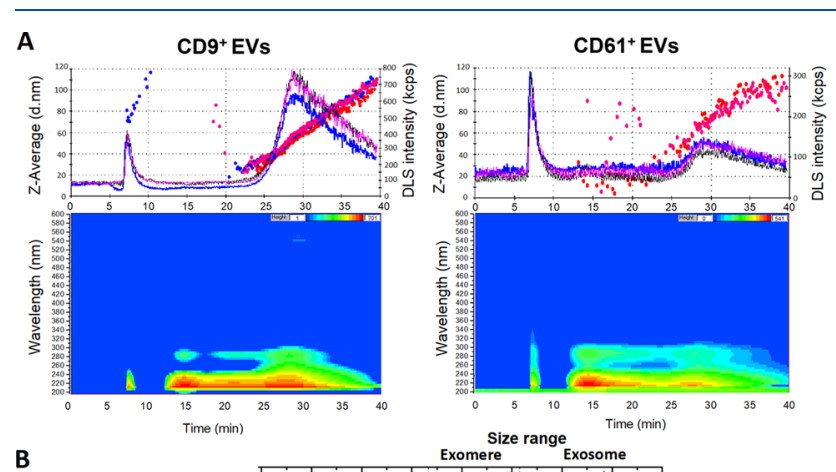

B
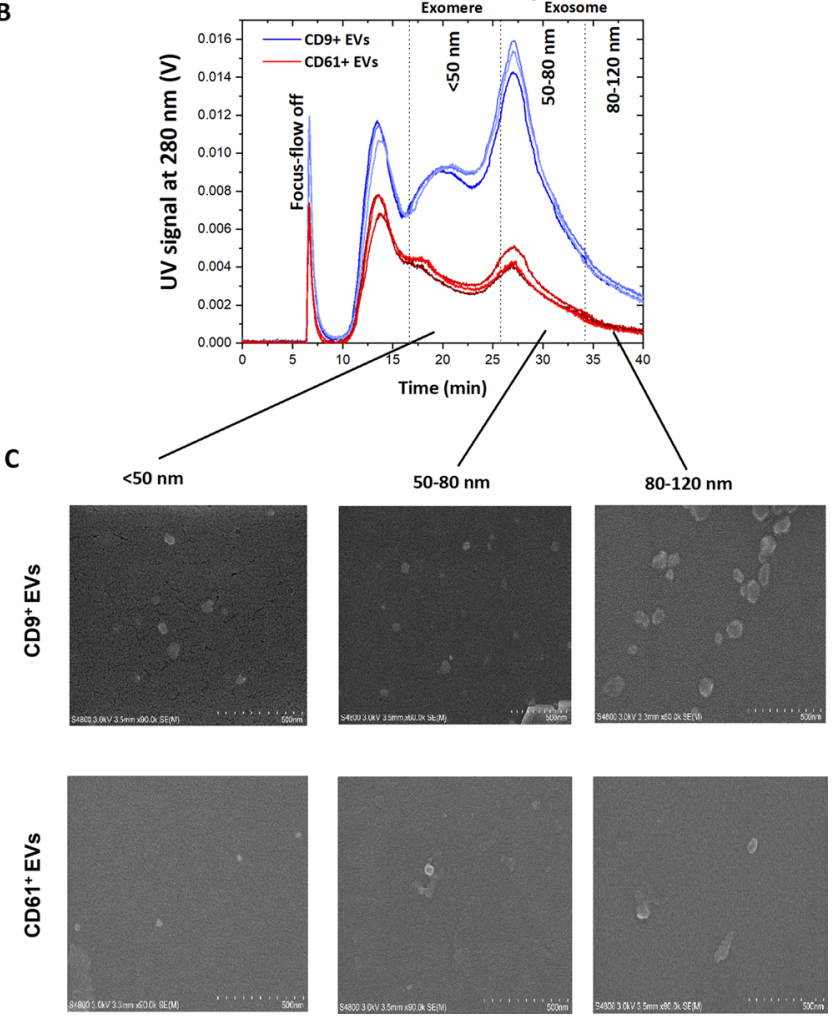

Figure 3. IAC-AsFlFFF analysis profiles after fractionating the $\mathrm{CD} 9^{+}$ and $\mathrm{CD}_{6} 1^{+} \mathrm{EV}$ isolates. Technical replicates $(n=3)$ of raw flow DLS data, the hydrodynamic diameter (dots as $Z$-Average) on top, and isoabsorbance plot of selected run at the bottom (A). Overlaid UV spectra $(280 \mathrm{~nm})$ from the technical replicates (B), and FESEM morphology of fractionated subpopulations (C) for $\mathrm{CD} 9^{+}$and $\mathrm{CD} 61^{+}$ EVs. combined fractions of the subpopulations (Figure 3C) agreed with hydrodynamic diameters obtained by DLS. The RSD of UV peak areas of $\mathrm{CD}^{+}$EVs was $2.9 \%$, while it was $4.2 \%$ for CD $61^{+}$EVs. The EVs in the size range of exomeres $(<50 \mathrm{~nm})$ were collected by combining fractions at retention times of 16-26 min, 50-80 $\mathrm{nm}$ sized exosomes at $27-34 \mathrm{~min}$, and $80-120 \mathrm{~nm}$ sized exosomes at 35-40 min. Surprisingly, the exomere sized EVs were also detected at relatively high concentrations, while they are reported ${ }^{10}$ to contain low levels of tetraspanin CD9 and integrins like CD61. The previously reported results on exomeres were, however, obtained from samples originating from cell lines and cell culture, whereas our IAC disks enriched exomere sized $\mathrm{CD}^{+}$and $\mathrm{CD}^{+} 1^{+} \mathrm{EV}$ s from all possible cells that secrete exomeres to plasma, thus collecting together all possible $\mathrm{CD}^{+}$and $\mathrm{CD}^{+} 1^{+}$exomeres. Even smaller sized particles than exomeres were also found at the retention time of $10-15 \mathrm{~min}$ in both cases (Figure 3B). The mean surface charges ( $\zeta$ potential) of the isolated exomere and exosome sized EVs were negatively charged (Figure S3), also agreeing with previously reported results. ${ }^{10}$ The $\mathrm{CD}^{+}<$ $50 \mathrm{~nm}$ EVs had a mean charge of $-14.1 \mathrm{mV}(n=9$ independent measurements for each technical replicate $n=3$ ), $-16.2 \mathrm{mV}$ for $50-80 \mathrm{~nm}$, and $-16.9 \mathrm{mV}$ for $80-120 \mathrm{~nm}$ subpopulations. While the $\mathrm{CD} 61^{+}<50 \mathrm{~nm}$ subpopulation had a mean charge of -15.1 and $-14.2 \mathrm{mV}$ for $50-80 \mathrm{~nm}$, and $-16.6 \mathrm{mV}$ for $80-120 \mathrm{~nm}$ subpopulations.

The IAC-AsFlFFF system resulted in faster and more selective isolation and fractionation for lipoproteins (38 samples/24 h) and EVs (18 samples/24 h) when compared to conventional standard methods, such as ultracentrifugation, ${ }^{8,27}$ with high repeatability, and minor sample loss and contamination. The IAC utilized high $\mathrm{pH}^{13,14}$ for the elution of biomacromolecules. However with on-line AsFlFFF the elution solution was immediately exchanged to PBS, avoiding long exposure to high $\mathrm{pH}$ and nonphysiological environment. The system was cost-effective and produced well-controlled final products needed especially in the EV-field. ${ }^{1}$ Additionally, it added significantly to the productivity of personnel and instruments, and quality of the data compared to our previous approaches for the isolation of same biomacromolecules. ${ }^{13,14,28}$

Amino Acid and Glucose Analysis of EV Subpopulations Isolated by On-line IAC-AsFIFFF. In plasma, amino acids are fundamentally involved in physiological activities, and their levels are used clinically for diagnostic purposes. EVs have also been found to carry amino acids along with other small metabolites. ${ }^{29}$ Therefore, the study of free amino acids found in EVs may elucidate their distinct biological roles and properties. In this study, we also developed an HILIC-MS/MS method for the analysis of free amino acids and sugars found in $\mathrm{CD}^{+}$and $\mathrm{CD}^{+} 1^{+} \mathrm{EV}$ subpopulations. Chromatograms with linearity and limit of detection of the method, and effect of the sample matrix on the results are found in the Supporting Information (Figures S4-S6, Tables S4 and S5).

We found that both $\mathrm{CD}^{+}$and $\mathrm{CD}^{+} 1^{+}$EVs shared not only similarities but also differences in terms of free amino acid concentrations as displayed in Figure 4A. Among all free amino acids, Ser was found to be the most abundant. It is worth mentioning that Ser is a nonessential amino acid, and is an important component in the synthesis of membrane lipids, including sphingolipids and phosphatidylserine. Both lipids are enriched in exosomal membranes. ${ }^{30,31}$ It is thus possible that free Ser was incorporated inside the exosomes during exosome formation processes. In addition, $\mathrm{CD} 61^{+} \mathrm{EV}$ subpopulations of 


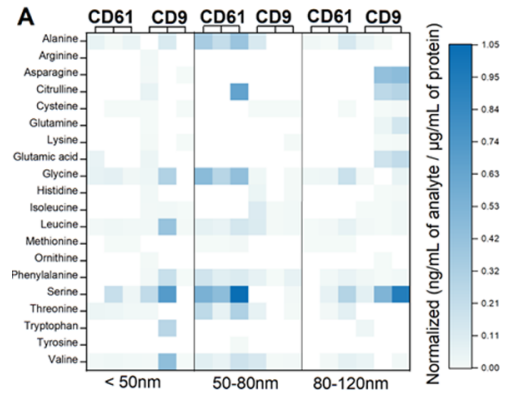

B

C

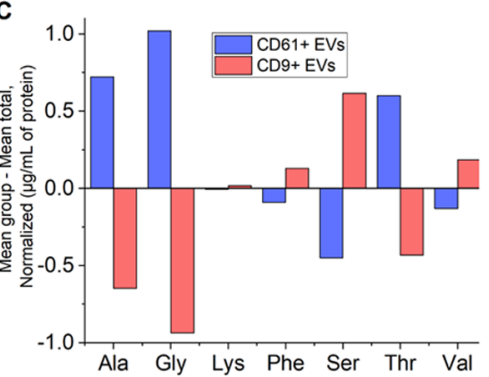

D
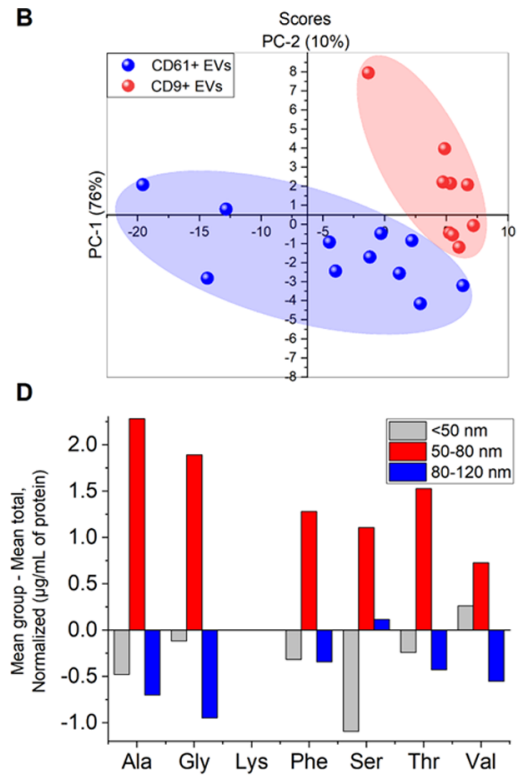

E

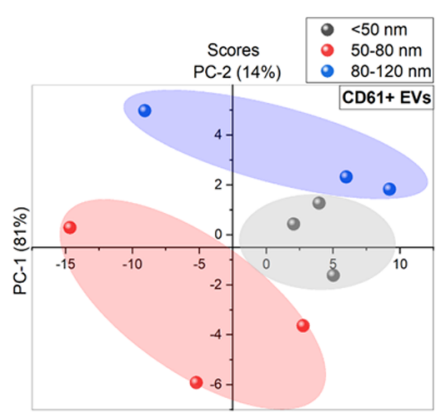

G

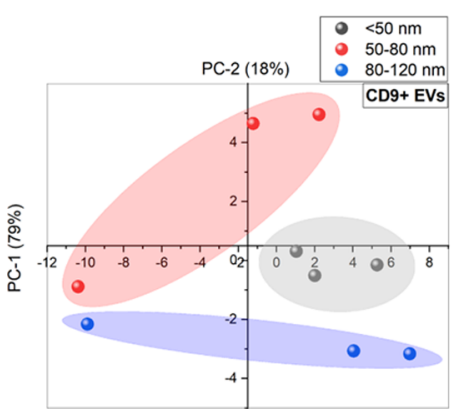

$\mathbf{F}$

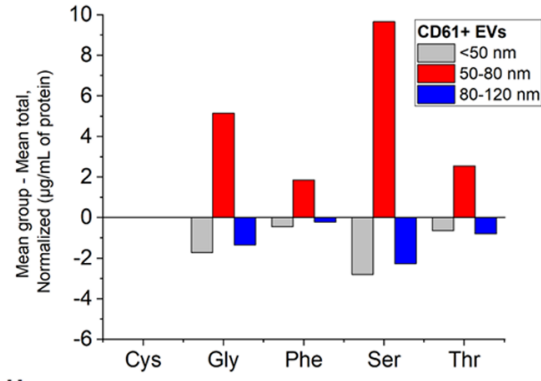

H

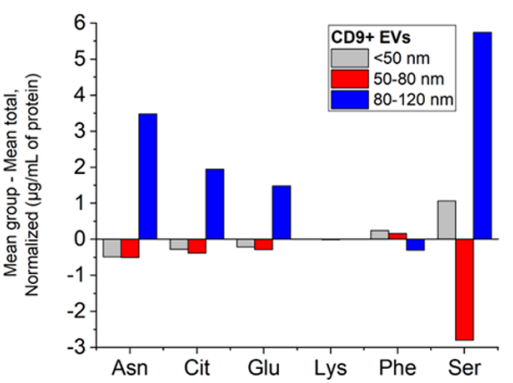

Figure 4. Multivariate analysis of amino acids found in $\mathrm{CD} 1^{+}$and $\mathrm{CD} 9^{+} \mathrm{EV}$ subpopulations. Heat map visualization of amino acids corresponding to their normalized concentrations $\left(\mathrm{ng} / \mathrm{mL}\right.$ per $\mu \mathrm{g} / \mathrm{mL}$ of total protein) (A). Scoring plot of PCA analysis showing differences between CD61 ${ }^{+}$and CD9 ${ }^{+}$EVs (B). Discriminant analysis of differences between amino acids found in CD61 ${ }^{+}$and $\mathrm{CD} 9^{+} \mathrm{EVs}(\mathrm{C})$. Discriminant analysis of differences between amino acids found between different sizes of combined EV subpopulations (D). Scoring plot of PCA analysis revealing differences between subpopulations of different sizes of $\mathrm{CD} 61^{+} \mathrm{EVs}(\mathrm{E})$. Discriminant analysis of differences between amino acids found between $\mathrm{CD} 61^{+} \mathrm{EV}$ subpopulations (F). Scoring plot of PCA analysis revealing differences between subpopulations of different sizes of CD9 ${ }^{+}$EVs (G). Discriminant analysis of differences between amino acids found between $\mathrm{CD}^{+} \mathrm{EV}$ subpopulations $(\mathrm{H})$.

exosomal size range $(50-80 \mathrm{~nm})$ contained the highest concentrations of free amino acids, while for $\mathrm{CD} 9^{+} \mathrm{EVs}$, the levels were the highest for the exosomal size range of $80-120$ $\mathrm{nm}$. The EVs $<50 \mathrm{~nm}$ (size range of exomeres) were least abundant in Ser, which indicates their nonmembranous nature as described by Zhang et al. ${ }^{10}$

To further visualize and clarify the differences between the two EV subpopulations, PCA and LDA analyses were used. The scoring plot obtained from PCA analysis (Figure 4B) revealed clear differences between $\mathrm{CD}^{+}$and $\mathrm{CD}^{+} 1^{+} \mathrm{EV}$. Based on the LDA results (Figure 4C), in which over $93 \%$ of samples were correctly classified, the differences between these two groups were majorly contributed by the following amino acids: Ala, Gly, Lys, Phe, Ser, Thr, and Val. The levels of Ala, Gly, and Thr, were significantly higher in $\mathrm{CD}^{+} 1^{+} \mathrm{EVs}$ compared to $\mathrm{CD}^{+}$EVs. Ala, Cys, Gly, Ser, and Thr are potentially involved in the biochemical pathway of gluconeogenesis from amino acids and can be directly converted to pyruvate. $^{32}$ In addition, Ala and Gly play major roles in immune responses by inhibiting apoptosis, ${ }^{33}$ as well as serving as an anti-inflammatory and immunomodulatory agent. ${ }^{34}$ $\mathrm{CD} 1^{+}$EVs have originated from platelets, and these findings support the role of platelets in defense mechanism and inflammation. ${ }^{35}$ Interestingly, based on the Western blot 
analysis previously reported, ${ }^{13}$ part of the $\mathrm{CD} 1^{+} \mathrm{EVs}$ also contained CD9. Thus, the differences from statistical analyses of $\mathrm{CD} 1^{+}$and $\mathrm{CD} 9^{+}$EVs are most likely due to subpopulation sets (containing only CD61 or only CD9) that do not overlap. Moreover, based on subpopulations, regardless of the EV origin, 50-80 nm subpopulation (in the size range of small exosomes) contained the highest levels of Ala, Gly, Ser, and Thr (Figure 4D), indicating that EVs in the size range of small exosomes are more likely to take part in gluconeogenesis compared to other subpopulations.

The differences among EVs of $<50 \mathrm{~nm}$ for the size range of exomeres and 50-80 and 80-120 nm for the size range of exosomes for both $\mathrm{CD}^{+}$and $\mathrm{CD}^{+} 1^{+} \mathrm{EVs}$ were further investigated (Figure 4E-H). The PCA analysis suggested a clear distinction among the three subpopulations of different sizes (Figure 4E,G). The good classification of the samples by the LDA models (90 and $100 \%$ of the samples correctly classified for $\mathrm{CD}^{+}$and $\mathrm{CD}^{+} 1^{+}$subpopulations, respectively) confirmed these results. In $\mathrm{CD}^{+} 1^{+}$subpopulations, Cys, Gly, Phe, Ser, and Thr, contributed to the differences in the size. These free amino acids were dominant in the 50-80 nm subpopulation, indicating that among $\mathrm{CD} 61^{+} \mathrm{EVs}$ in the size range of small exosomes take part in gluconeogenesis. On the other hand, $\mathrm{CD}^{+} \mathrm{EV}$ subpopulations were different due to other free amino acids. Asn, Cit, Glu, Lys, Phe, and Ser contributed significantly in CD9 ${ }^{+}$EVs (Figure $4 \mathrm{H}$ ). The levels of Asn, Cit, Glu, and Ser, were the highest in the 80-120 nm subpopulation of the large exosomal size range. Interestingly the levels of Ser were significantly higher in the 80-120 nm subpopulation compared to $50-80 \mathrm{~nm}$ subpopulation among $\mathrm{CD}^{+}$EVs. The differences also confirm distinct cellular origins of $\mathrm{CD}^{+}$and $\mathrm{CD} 61^{+} \mathrm{EVs}$ in the exosomal size range.

In addition to amino acids, glucose levels of EVs were measured. It was found that all subpopulations of $\mathrm{CD} 61^{+} \mathrm{EVs}$ contained glucose in the concentration range of $\mathrm{pmol} / \mathrm{mL}$. The presence of glucose can possibly be ascribed to the $\mathrm{CD} 61^{+} \mathrm{EV}$ fractions being rich in amino acids essential for gluconeogenesis. However, in $\mathrm{CD}^{+}$subpopulations only $50-80 \mathrm{~nm}$ subpopulation contained glucose. Importantly, these findings revealed that different free amino acids and monosaccharide concentrations were found in EV subpopulations isolated and fractionated by on-line IAC-AsFlFFF. These differences can be further utilized as key factors to differentiate the subpopulations of EVs (exomeres, and small and large exosomes) from different cellular origin, as well as to confirm distinct properties and functions of these particles in the human physiology. The functional activity of isolated and fractionated EVs still needs to be assessed. The results of this study demonstrated that online IAC-AsFlFFF can be utilized for biomarker and composition studies.

\section{CONCLUSIONS}

On-line coupled IAC-AsFlFFF allowed the reliable and fast isolation and fractionation of challenging biomacromolecules from human plasma, resulting in high purity subpopulations with high yields. The fully automated on-line system could process $18-38$ samples in $24 \mathrm{~h}$ with only minor operator involvement. Due to a gentle fractionation step, apoB-100 containing lipoproteins, used in the testing step, and intact EV subpopulations under $120 \mathrm{~nm}$ were successfully obtained as confirmed by DLS and FESEM. The EV subpopulations were further exposed to particle surface charge as well as free amino acid and sugar composition studies. The results revealed that there were significant differences between cellular origin of EVs and even within subpopulations $<120 \mathrm{~nm}$. In addition to three different ligands employed in this study, the flexible system is applicable to any other ligand that can be immobilized on the monolithic disk column.

\section{ASSOCIATED CONTENT}

\section{Supporting Information}

The Supporting Information is available free of charge at https://pubs.acs.org/doi/10.1021/acs.analchem.0c01986.

Chemicals and reagents, instrumentation, optimized multiple reaction monitoring parameters for amino acids and sugar, IAC-AsFIFFF cycles, process cycles used in the IAC, optimal AsFlFFF conditions, optimal time for six port valve timer, $\zeta$ potential of $\mathrm{CD}^{+}$and $\mathrm{CD} 1^{+} \mathrm{EV}$ subpopulations, extracted-ion chromatograms based on MRM of a standard mixture containing amino acids, glucose, internal standards, and 50-80 nm $\mathrm{CD} 1^{+} \mathrm{EV}$ subpopulation, total ion chromatograms of blank, calibration curves for amino acids and glucose, recovery percentages of target amino acids and glucose based on standard addition analyses (PDF)

\section{AUTHOR INFORMATION}

\section{Corresponding Author}

Marja-Liisa Riekkola - Department of Chemistry, University of Helsinki, FI-00014 Helsinki, Finland; 이이.org/0000-

0001-7519-9892; Email: marja-liisa.riekkola@helsinki.fi

\section{Authors}

Evgen Multia - Department of Chemistry, University of Helsinki, FI-00014 Helsinki, Finland; (1) orcid.org/00000002-8717-8842

Thanaporn Liangsupree - Department of Chemistry, University of Helsinki, FI-00014 Helsinki, Finland

Matti Jussila - Department of Chemistry, University of Helsinki, FI-00014 Helsinki, Finland

Jose Ruiz-Jimenez - Department of Chemistry, University of Helsinki, FI-00014 Helsinki, Finland

Marianna Kemell - Department of Chemistry, University of Helsinki, FI-00014 Helsinki, Finland; 이이.org/00000002-3583-2064

Complete contact information is available at:

https://pubs.acs.org/10.1021/acs.analchem.0c01986

\section{Author Contributions}

The manuscript was written through contributions of all authors.

\section{Notes}

The authors declare the following competing financial interest(s): Patent application.

\section{ACKNOWLEDGMENTS}

This study was supported by the Research Council for Natural Sciences and Engineering, Academy of Finland (grant number 1311369). The authors would like to thank Dr. Matti Jauhiainen, Jari Metso, and other personnel of Minerva Foundation Institute for Medical Research for providing plasma samples and for their support during the studies. Dr. Katariina Öörni from Wihuri Research Institute is thanked for providing lipoprotein samples. Shu $\mathrm{Yi} \mathrm{Fu}$ is thanked for assisting with part of the experiments. 


\section{REFERENCES}

(1) Colao, I. L.; Corteling, R.; Bracewell, D.; Wall, I. Trends Mol. Med. 2018, 24, 242-256.

(2) Hyötyläinen, T.; Riekkola, M.-L. Anal. Bioanal. Chem. 2004, 378 , 1962-1981.

(3) Yohannes, G.; Sneck, M.; Varjo, S. J. O.; Jussila, M.; Wiedmer, S. K.; Kovanen, P. T.; Öörni, K.; Riekkola, M. L. Anal. Biochem. 2006, 354, 255-265.

(4) Lu, M.; Gursky, O. Biomol. Concepts 2013, 4, 501-518.

(5) Sódar, B. W.; Kittel, Á.; Pálóczi, K.; Vukman, K. V.; Osteikoetxea, X.; Szabó-Taylor, K.; Németh, A.; Sperlágh, B.; Baranyai, T.; Giricz, Z.; Wiener, Z.; Turiák, L.; Drahos, L.; Pállinger, E.; Vékey, K.; Ferdinandy, P.; Falus, A.; Buzás, E. I. Sci. Rep. 2016, 6, No. 24316.

(6) Kalluri, R.; LeBleu, V. S. Science 2020, 367, No. eaau6977.

(7) Toth, P. Vasc. Health Risk Manage. 2016, 171-183.

(8) Okazaki, M.; Usui, S.; Hosaki, S. Handbook. Lipoprotein Test, 2000.

(9) Toft-Petersen, A. P.; Tilsted, H. H.; Aarøe, J.; Rasmussen, K.; Christensen, T.; Griffin, B. A.; Aardestrup, I. V.; Andreasen, A.; Schmidt, E. B. Lipids Health Dis. 2011, 10, 21.

(10) Zhang, H.; Freitas, D.; Kim, H. S.; Fabijanic, K.; Li, Z.; Chen, H.; Mark, M. T.; Molina, H.; Martin, A. B.; Bojmar, L.; Fang, J.; Rampersaud, S.; Hoshino, A.; Matei, I.; Kenific, C. M.; Nakajima, M.; Mutvei, A. P.; Sansone, P.; Buehring, W.; Wang, H.; Jimenez, J. P.; Cohen-Gould, L.; Paknejad, N.; Brendel, M.; Manova-Todorova, K.; Magalhães, A.; Ferreira, J. A.; Osório, H.; Silva, A. M.; Massey, A.; Cubillos-Ruiz, J. R.; Galletti, G.; Giannakakou, P.; Cuervo, A. M.; Blenis, J.; Schwartz, R.; Brady, M. S.; Peinado, H.; Bromberg, J.; Matsui, H.; Reis, C. A.; Lyden, D. Nat. Cell Biol. 2018, 20, 332-343.

(11) Mathieu, M.; Martin-Jaular, L.; Lavieu, G.; Théry, C. Nat. Cell Biol. 2019, 21, 9-17.

(12) de Jong, O. G.; Kooijmans, S. A. A.; Murphy, D. E.; Jiang, L.; Evers, M. J. W.; Sluijter, J. P. G.; Vader, P.; Schiffelers, R. M. Acc. Chem. Res. 2019, 52, 1761-1770.

(13) Multia, E.; Tear, C. J. Y.; Palviainen, M.; Siljander, P.; Riekkola, M. L. Anal. Chim. Acta 2019, 1091, 160-168.

(14) Liangsupree, T.; Multia, E.; Metso, J.; Jauhiainen, M.; Forssén, P.; Fornstedt, T.; Öörni, K.; Podgornik, A.; Riekkola, M. L. Sci. Rep. 2019, 9, No. 11235.

(15) Yohannes, G.; Jussila, M.; Hartonen, K.; Riekkola, M.-L. J. Chromatogr. A 2011, 1218, 4104-4116.

(16) Zhang, X.; Li, Y.; Shen, S.; Lee, S.; Dou, H. TrAC, Trends Anal. Chem. 2018, 108, 231-238.

(17) Rico, E.; González, O.; Blanco, M. E.; Alonso, R. M. Anal. Bioanal. Chem. 2014, 406, 7641-7652.

(18) Yoshida, K.; Horii, K.; Fujii, Y.; Nishio, I. ChemPhysChem 2014, $15,2909-2912$

(19) Helin, A.; Sietiö, O.-M.; Heinonsalo, J.; Bäck, J.; Riekkola, M.L.; Parshintsev, J. Atmos. Chem. Phys. 2017, 17, 13089-13101.

(20) Lowry, O. H.; Rosebrough, N. J.; Farr, A. L.; Randall, R. J. J. Biol. Chem. 1951, 193, 265-275.

(21) Smith, P. K.; Krohn, R. I.; Hermanson, G. T.; Mallia, A. K.; Gartner, F. H.; Provenzano, M. D.; Fujimoto, E. K.; Goeke, N. M.; Olson, B. J.; Klenk, D. C. Anal. Biochem. 1985, 150, 76-85.

(22) R Core Team. R: A Language and Environment for Statistical Computing; R Foundation for Statistical Computing: Vienna, Austria, 2019.

(23) Multia, E.; Sirén, H.; Andersson, K.; Samuelsson, J.; Forssén, P.; Fornstedt, T.; Öörni, K.; Jauhiainen, M.; Riekkola, M.-L. Anal. Biochem. 2017, 518, 25-34.

(24) Witwer, K. W.; Théry, C. J. Extracell. Vesicles 2019, 8, No. 1648167.

(25) Kowal, J.; Arras, G.; Colombo, M.; Jouve, M.; Morath, J. P.; Primdal-Bengtson, B.; Dingli, F.; Loew, D.; Tkach, M.; Théry, C. Proc. Natl. Acad. Sci. U.S.A. 2016, 113, E968-77.

(26) Morani, M.; Mai, T. D.; Krupova, Z.; Defrenaix, P.; Multia, E.; Riekkola, M.-L.; Taverna, M. Anal. Chim. Acta 2020, 1128, 42-51.
(27) Coumans, F. A. W.; Brisson, A. R.; Buzas, E. I.; Dignat-George, F.; Drees, E. E. E.; El-Andaloussi, S.; Emanueli, C.; Gasecka, A.; Hendrix, A.; Hill, A. F.; Lacroix, R.; Lee, Y.; van Leeuwen, T. G.; Mackman, N.; Mäger, I.; Nolan, J. P.; van der Pol, E.; Pegtel, D. M.; Sahoo, S.; Siljander, P. R. M.; Sturk, G.; de Wever, O.; Nieuwland, R. Circ. Res. 2017, 120, 1632-1648.

(28) Gan, N.; Multia, E.; Sirén, H.; Ruuth, M.; Öörni, K.; Maier, N. M.; Jauhiainen, M.; Kemell, M.; Riekkola, M. L. Anal. Biochem. 2016, $514,12-23$.

(29) Ramirez, M. I.; Amorim, M. G.; Gadelha, C.; Milic, I.; Welsh, J. A.; Freitas, V. M.; Nawaz, M.; Akbar, N.; Couch, Y.; Makin, L.; Cooke, F.; Vettore, A. L.; Batista, P. X.; Freezor, R.; Pezuk, J. A.; Rosa-Fernandes, L.; Carreira, A. C. O.; Devitt, A.; Jacobs, L.; Silva, I. T.; Coakley, G.; Nunes, D. N.; Carter, D.; Palmisano, G.; Dias-Neto, E. Nanoscale 2018, 10, 881-906.

(30) Inuzuka, M.; Hayakawa, M.; Ingi, T. J. Biol. Chem. 2005, 280, 35776-35783.

(31) Skotland, T.; Hessvik, N. P.; Sandvig, K.; Llorente, A. J. Lipid Res. 2019, 60, 9-18.

(32) The Molecular Nutrition of Amino Acids and Proteins. In $A$ Volume in the Molecular Nutrition Series, Dardevet, D., Ed.; Academic Press, 2016.

(33) Li, P.; Yin, Y.-L.; Li, D.; Kim, S. W.; Wu, G. Br. J. Nutr. 2007, 98, 237-252.

(34) Zhong, Z.; Wheeler, M.; Li, X.; M, F.; et al. Curr. Opin. Clin. Nutr. Metab. Care 2003, 6, 229-240.

(35) Stokes, K. Y.; Granger, D. N. J. Physiol. 2012, 590, 1023-1034. 